\title{
Chemotherapy-Knowledge and Handling Practice of Nurses Working in a Medical University of Nepal
}

\author{
Ramanand Chaudhary, Basant Kumar Karn \\ Department of Child Health Nursing, B. P. Koirala Institute of Health Sciences, Dharan, Nepal. \\ Email: ramanandachaudhary@yahoo.com
}

Received November $22^{\text {nd }}, 2011$; revised December $24^{\text {th }}, 2011$; accepted January $7^{\text {th }}, 2012$

\begin{abstract}
Background: Many antineoplastic agents are known to be teratogenic and mutagenic to humans. Nurses are the main groups that are exposed to these drugs in hospital setting. Generally, the occupational activities that pose to greatest risk of exposure are the preparation and administration of antineoplastic agents, cleaning of chemotherapy spills, and handling of patient excreta. Objective: The objectives of this study were to evaluate the knowledge of nurse regarding the way of exposure of Cytotoxic Drugs (CDs) and to determine the current patterns of use of personal protective equipments while handling antineoplastic chemotherapeutic agents. Methods: An analytic cross sectional study was carried out at BPKIHS Dharan. The study was carried out on 125 nurses. The random sampling technique was used to select the study subjects using structured and semi-structured questionnaire. Collected data were analyzed using descriptive and inferential statistics. Result: More than $92 \%$ of participants reported usually wearing gloves during chemotherapy handling; 6\% reported using laboratory coats as protective garments. Usual use of face and respiratory protection was less than $5 \%$. Chemotherapy was reported to be prepared in nursing station where there are no laminar airflow hoods in $100 \%$ of work settings. None of the subjects have reportedly provided any type of medical monitoring. Conclusion: Use and availability of gloves have increased but personal protective equipment like protective garments, face and respiratory protective, when handling chemotherapy have decreased and medical monitoring of exposed employees still is neither widely practiced nor consistent with Occupational Safety and Health Administration (OSHA) guidelines.
\end{abstract}

Keywords: Nurses; Chemotherapy; Knowledge; Practice

\section{Introduction}

Today cancer patients are diagnosed earlier than in the past, and many receive multiple courses of chemotherapy for a longer period of time [1]. Many antineoplastic drugs are known to be carcinogenic, teratogenic and mutagenic to humans [2]. Recent studies show the increase in the potential risks due to occupational exposure to Cytotoxic Drugs (CDs). Occupational exposure is important because physical, economic and socio cultural factors are major determinants of behaviour relevant to cancer. Exposure and absorption occur during the preparation and administration in health care practice [3]. Nurses and pharmacists are the main groups that are exposed to these drugs in the ambulatory care and hospital settings [4].

Exposure may result from direct contact via skin or eyes [5] and inhalation of droplets aerosolization, mainly because of inappropriate hygienic behaviour such as eating, drinking or smoking during preparation, administration, or disposal of CDs [6]. Among the possible chronic effects of CDs are cancer, fertility problems, long term genetic changes in off-spring, abortion and abnormalities in the fetus [7].

Interest in the issue of safe handling of CDs began in the late 1970s. More recently, in many countries, national health authorities' concern has been focused on promoting actions aimed to protect health of the personnel handling these drugs. In order to promote compliance among health care providers for better use of safety measures, guidelines and clear procedures were established by institutions such as OSHA. Ministry of Health and Turkish Society of Oncology Nursing are working on the guidelines on handling and preparing of CDs.

Although there has been an increased awareness and concern regarding the issue of safe handling of CDs, many nurses still do not follow the guidelines and procedures in the hospital settings and are not using the recommended safety equipment [8]. In our hospital especially nurses are exposed while preparing and administrating the CDs. For that reason nurses' information about the possible toxicities and the protection measures used while preparing and administering these drugs is gaining more and more importance. 


\section{Materials and Methods}

An analytic cross sectional study carried out in February 2006 in BP Koirala University teaching hospital. The target group of the study was 125 nurses who work with Cytotoxic Drugs (CDs). The nurses were from internal medicine (55), surgery (33), pediatrics (14), gynecology (13), ENT (10) departments. 125 of the nurses participated in the study. The coverage was $86.9 \%$.

Two self reported questionnaires were used in order to collect the data of the study. The questionnaire was tested in a pilot study and was discussed in a specialists' panel and some of the questions were modified according to the results. The first questionnaire covered following items of socio demographic data such as age, education, marital status, number of years as registered nurse and oncology nurse, personal, occupational and exposure history, safe behaviour while dealing with the CDs, complaints due to CDs exposure and the source of information on CDs. The second questionnaire aimed to evaluate the level of knowledge of the nurses on the way of exposure of CDs and the protective measures. The level of knowledge was assessed in two categories using the mean knowledge score as cut off point. The scores above the mean were assessed as sufficient. Direct observations were made over a period of half a day in different clinical settings. The purpose of the observation was to validate the exposed nurses' compliance with the guidelines in practice and their actual use of protective measures while handling the CDs. Student's T test and variance analysis were used to compare the data for groups.

\section{Results}

125 registered nurses participated in this study. The mean age of the study population was $28.9 \pm 6.32$ years. One third of the nurses were married. $78.4 \%$ of the nurses had university degree. Majority (89.6\%) of the nurses worked in different clinical settings during an 8 hour day shift. Mean duration in the profession was $5.21 \pm 1.25$ and mean duration of work with CDs therapy was $3.32 \pm$ 0.52 years (Table $\mathbf{1}$ ).

The nurses were asked for the places that they prepare the CDs. None of the nurses prepare the CDs in proper preparation cabins. $17 \%$ of the nurses reported that they prepare the CDs in treatment room, $83 \%$ of the nurse prepare the CDs in working environment where there was no proper aspiration system. Frequency of CDs preparation is given in Table 2.

Changing the bed sheets and/or the naso-gastric and changing urinary catheter of the patients who are in CD therapy is categorized as the risky clinical activities. Evaluation of the "risky clinical activities" during the daily routine is given in Table 3 .
Table 1. The characteristics of the study population.

\begin{tabular}{|c|c|c|}
\hline Characteristics & Frequency & Percentage \\
\hline \multicolumn{3}{|l|}{ Cadre } \\
\hline Staff Nurse & 98 & 78.4 \\
\hline Auxiliary Nurse Midwife & 27 & 21.6 \\
\hline Age of nurses’ (Years) & $28.9 \pm 6.32$ & \\
\hline Status & & 36.0 \\
\hline Married & 45 & 64.0 \\
\hline Single & 80 & \\
\hline Education & & 78.4 \\
\hline Certificate in Nursing & 98 & 21.6 \\
\hline Auxiliary Nurse Midwife & 27 & \\
\hline Duration in the profession (Years) & $5.21 \pm 1.25$ & \\
\hline \multicolumn{3}{|l|}{$\begin{array}{l}\text { Duration of work with CDs } \\
\text { (Years) }\end{array}$} \\
\hline Type of work & $3.32 \pm 0.52$ & 89.6 \\
\hline Shift work & & 10.4 \\
\hline 8 hour day shift & 112 & \\
\hline Primary Practice Setting & 13 & 44.0 \\
\hline Internal medicine & & 26.4 \\
\hline General Surgery & 55 & 11.2 \\
\hline Pediatric & 33 & 10.4 \\
\hline Gynecology Ward & 14 & 8.0 \\
\hline \multirow[t]{2}{*}{ Ear, Nose \& throat Ward } & 13 & \\
\hline & 10 & \\
\hline
\end{tabular}

Table 2. Practices of cytotoxic drugs preparation.

\begin{tabular}{lc}
\hline Practices of CDs Preparation & Percentage \\
\hline Frequency of CD’s preparation & 39 \\
Once in two days & 25 \\
Once in three days & 21 \\
Once in four days & 10 \\
Once in five days & 04 \\
Few than once in a week & \\
Drug preparation area & 0 \\
Specially designed room & 17 \\
Treatment room & 83 \\
Nurse's station (Duty area) & \\
\hline
\end{tabular}

Table 3. Practice of risky clinical activities in working environment.

\begin{tabular}{lc}
\hline Risky clinical activities & Percentage \\
\hline Changing the bed sheets & 33.5 \\
Changing naso-gastric tubes & 25.2 \\
Changing urinary catheter & 21.6 \\
Handling excreta & 11.0 \\
Changing I/V line and/or cannula & 96.6 \\
\hline
\end{tabular}

\section{Usage of Protective Equipment}

Usage of protective equipment during CDs therapy preparation and "risky clinical activities" was evaluated. $92 \%$ of the nurses used gloves, $5 \%$ used surgical masks during CDs therapy preparation. None of the nurses used all of the protective equipments, while $62 \%$ used gloves and surgical mask together. 


\section{Nurses' Source of Information about CD's}

86.3\% of nurses received information about CDs from text books and internet followed by nursing administration (5.2\%), nursing association (2.5\%) and mass media (1.5\%).

None of the nurses received training program about CDs. The mean knowledge score of the nurses was 61.32 \pm 17.12 (minimum 0, maximum 100). Only $29 \%$ of the study group was above the groups' mean score.

According to the topics the mean scores were as follows; Mean score of knowledge about antineoplastic agent is $26 \pm 13$, about the prevention is $35 \pm 9$; about the way of exposure is $33 \pm 26$.

Significant differences were found between the mean scores of knowledge of the nurses who had formal information about CDS, compared with the groups who had no formal information about CDs. The knowledge score of the nurses who use at least one protective measure was significantly higher than who don't use any protective measure (Table 4).

\section{Discussion}

The aim of this study was to evaluate the level of knowledge of nurses on CDs and their actual usage of safety measures while handling the CDs. The findings indicate that the level of knowledge of the nurses on this issue is not satisfactory. The topics "properties of antineoplastics" and "the prevention" were the subjects where the nurses got the lowest scores. In previous studies, it is reported that the staff handling the CDs don't have a satisfactory level of knowledge regarding the risk factors [9]. This lack of knowledge on preventive measures is of concern because it increases the health workers' unsafe behaviour. Participating in a training program created significant difference on the level of knowledge; the training of all staff involved with any aspect of the handling of hazardous drugs is one of the three essential elements described in the Occupational Safety and Health Administration guidelines [10]. The main source of in- formation remains to be the hospital administration while Vollono's study reported that the health structure wasn't the main source of information for their respondents [11]. No significant differences were found in the mean scores of knowledge by preparation area of CDs, and frequency of risky behaviours in working environment.

Results about the nurses' safety behaviours and usage of recommended health safety measures showed that, notwithstanding the rules and regulations pertaining to CDs, nurses did not comply to them fully. Valanis reported that beliefs about what protection was required had a stronger correlation with actual use than did policy content [12]. In this study, nearly half of the nurses (62\%) had at least one of the risky behaviours in the CDs handling area. In a previous study, it was reported that $94 \%$ of the nurses drink and smoke in the preparation area of CDs [13]. The findings about the use of personal protective equipment showed that none of the nurses were using the four protective equipments necessary during the handling of CDs and the "risky clinical activities", respectively. As reported in the previous studies, the majority of the nurses have integrated glove use into their practice [14]. The current study noted an increase in the use of gloves and mask versus the previous study of Oncology Nursing Society in Turkey [15]. The use of mask, working suit and goggles continue to be limited. Nurses who had higher knowledge scores reported using at least one personal protective equipment significantly more frequently than the nurses who had lower knowledge scores.

Table 4. Nurses' knowledge means scores according to influencing factors.

\begin{tabular}{ccccc}
\hline Influencing Factors & Response & No. & Mean \pm sd & Remarks \\
\hline Received formal information about CDs & Received & 12 & $68.82 \pm 10.07$ & $\mathrm{p}=0.001$ \\
Preparation area of CDs & Not received & 113 & $60.42 \pm 15.24$ & $\mathrm{p}=0.29$ \\
& & & & \\
& Proper & 10 & $65.53 \pm 11.95$ & $\mathrm{p}=0.24$ \\
Preparation/ Administration of CDs & Not proper & 115 & $59.25 \pm 18.76$ & $\mathrm{p}=0.68$ \\
Risky Behaviors in working area & Every day/Once in two days & 39 & $65.92 \pm 12.30$ & $59.41 \pm 17.02$ \\
Usage of protective equipment & Other & 86 & $68.47 \pm 10.73$ & $\mathrm{p}=0.000$ \\
\end{tabular}


The findings showed that the working place was not a safe environment; nurses reported that their working environment had no proper aspiration system. Although some of previous studies report similar findings [16,17] some studies especially in the most developed countries reported that the majority were preparing CDs in a laminar air flow hood $[18,19]$. Based on this survey, the use of proper preparation cabins has not increased in hospitals of developing country like Nepal.

\section{Conclusion}

The level of knowledge of the nurses about antineoplastic drugs is not satisfactory. The awareness of the nurses handling the CDs is of concern because it is important in raising standards of safety. In service training is a very effective tool to increase the level of knowledge. This study revealed also the necessity of the improvement of the work environment and the availability of the protective equipment. As the primary prevention measures involve the least possible exposure to CDs, information regarding the updated guidelines should be disseminated both at the practice and administration levels. A safety committee in the hospital should ensure the appropriate implementation of safety policies; keep the staff informed about the procedures for safety handling of CDs.

\section{Acknowledgements}

The authors sincerely thanks to research committee of BPKIHS for providing opportunity to carry out this research study and the subjects for their co-operation during data collection.

\section{REFERENCES}

[1] S. Ben-Ami, J. Shaham, S. Rabin, A. Melzer and J. Ribak, “The Influence of Nurses' Knowledge, Attitude, and Health Believe on their Safe Behaviour with Cytotoxic Drugs in Israel," Cancer Nursing, Vol. 24, No. 3, 2001, pp. 192200. doi:10.1097/00002820-200106000-00005

[2] S. Burgaz and B. Karahalil, "Urinary Cyclophosphamide Excertion and Micronuclei Frequencies Lymphocytes and in Exfoliated Buccal Epithelial Cells of Nurses Handling Antineoplastics," Mutation Research, Vol. 439, No. 1, 1999, pp. 97-104.

[3] S. Ensslin Angela, R. Huber and P. Angelika, "Biological Monitoring of Hospital Pharmacy Personnel Occupationally Exposed to Cytostatic Drugs: Urinary Excretion and Cytogenetic Study," International Archives of Occupational Environmental Health, Vol. 70, No. 3, 1997, pp. 205-258. doi:10.1007/s004200050208

[4] C. Vollono, G. Badoni and G. Petrelli "Risk Perception and Self Assessment of Exposure to Antineoplastic Agents in a Group of Nurses and Pharmacists," Giornale Italiano di Medicina del Lavoro ed Ergonomia, Vol. 24, No. 1, 2002, pp. 49-55.
[5] P. J. Sessink, B. C. Wittenhorst, R. B. Anzion and R. P. Bos, "Exposure of Pharmacy Technicians to Antineoplastic Agents; Reevaluation after Additional Protective Measures," Archives of Environmental Health, Vol. 52, No. 3, 1997, pp. 240-244. doi:10.1080/00039899709602893

[6] E. Nygren and C. Lundgren, "Determination of Platinum in Workroom Air and in Blood and Urine from Nursing Staff Attending Patients Receiving Cisplatin Chemotherapy," International Archives of Occupational Environmental Health, Vol. 70, No. 3, 1997, pp. 209-214. doi:10.1007/s004200050209

[7] OSHA Technical Manual, "Controlling Occupational Exposure to Hazardous Drugs,” 5th Edition, OSHA Publication, Washington DC, 1999.

[8] G. Kubilay and H. Fesci Erdem, "Evaluation of the Status of the Nurses Preparing and Administrating CDs," Oncology Nurses' Association, Vol. 6, 1997, pp. 7-15.

[9] C. Habib and S. Karam, "Handling of Antineoplastic Products and Nurses' Knowledge,” Le Journal Medical Libanais, Vol. 40, No. 4, 1992, pp. 182-186.

[10] International Agency for Research on Cancer (IARC), "IARC Monographs on the Evaluation of Carcinogenic Risk of Chemicals to Humans: Some Antineoplastic and Immunosuppressive Agents,” Vol. 26, IARC, Lyon, 1981, pp. 370-384.

[11] S. Krstev, B. Perunicic and A. Vidakovic, "Work Practice and Some Adverse Health Effects in Nurses Handling Antineoplastic Drugs,” Le Medicina del Lavoro, Vol. 94, No. 4, 2003, pp. 432-439.

[12] S. Martin, E. Larson, "Chemotherapy-Handling Practices of Outpatient and Office-Based Oncology Nurses,” Oncology Nursing Forum, Vol. 30, No. 4, 2003, pp. 575-581. doi:10.1188/03.ONF.575-581

[13] G. Aydemir, N. Sogukpinar and E. Türkistanli, "Prevention and Health Education: How Recent Advances in the Science and Art of Health Education Have Been Applied in Practical Ways within Medical and Other Settings for Prevention of Public Health," Asian Pacific Journal of Cancer Prevention, Vol. 4, No. 1, 2003, pp. 71-74.

[14] S. Mastour, Al-Ghamdi, H. Zaki and Al-Mustafa, "The Handling of Anticancer Drugs in Riyadh and the Eastern Province," Annals of Saudi Medicine, Vol. 17, No. 2, 1997, pp. 257-259.

[15] C. Schreiber, K. Radon K, A. Pethran, R. Schierl, K. Hauff, C. H. Grimm, et al., "Uptake of Antineoplastic Agents in Pharmacy Personnel, Part II: Study of Work Related Risk Factors," International Archives of Occupational and Environmental Health, Vol. 76, No. 1, 2002, p. 11.

[16] G. Micoli, R. Turci, M. Arpellini and C. Monia, "Determination of 5-Fluorouracil in Environmental Samples by Solid-phase Extraction and High-Performance Liquid Chromatography with Ultraviolet Detection,” Journal of Chromatography, Vol. 50, No. 1, 2001, pp. 25-32.

[17] P. J. Sessink, K. A. Boer, A. P. Scheefhals, R. B. Anzion and R. P. Bos, "Occupational Exposure to Antineoplastic Agents at Several Departments in a Hospital. Environmental Contamination and Excretion of Cyclophosphamide and Ifosfamide in Urine of Exposed Workers," International Archives of Occupational and Environmental 
Health, Vol. 64, No. 2, 1992, pp. 105-112. doi:10.1007/BF00381477

[18] P. J. Sessink, M. C. Van de Kerkhof and R. B. Anzion, "Environmental Contamination and Assessment of Exposure to Antineoplastic Agents by Determination of Cyclophosphamide in Urine of Exposed Pharmacy Technicians: Is Skin Absorption an Important Exposure Route?”
Archives of Environmental Health, Vol. 49, No. 3, 1994, pp. 165-169. doi:10.1080/00039896.1994.9940377

[19] P. J. Sessink, A. J. Verplanke, R. F. Herber and R. P. Bos, "Occupational Exposure to Antineoplastic Agents and Parameters for Renal Dysfunction,” International Archives of Occupational and Environmental Health, Vol. 69, No. 3, 1997, pp. 215-218. doi:10.1007/s004200050139 